\title{
Recuperación del Cristo divino preso de Lomas de Bracho en Zacatecas, Zacatecas
} (México)

\author{
Diana Ugalde Romo
}

$\checkmark$ nos días antes de la Procesión del Silencio del 2012, el 22 de marzo, una escultura policromada denominada Cristo divino preso (Figura 1), cuya temporalidad data de finales del siglo XIX (Berthier 2003:121), fue sustraída ilícitamente de una repisa de la sacristía de la capilla de la localidad de San Juan Bautista en Lomas de Bracho, Zacatecas, México.

Dos meses después de este incidente, la policía estatal del municipio de Ojo Caliente, Zacatecas, notificó a la dependencia del Instituto Nacional de Antropología e Historia (INAH) del lugar, el Centro INAH Zacatecas, que la escultura se había hallado afortunadamente. Éste, una vez que se realizó una serie de trámites legales, llevó a cabo un proyecto de conservación-restauración de la obra, a cuyo término, el Cristo divino preso regresó a su sitio de procedencia, con el júbilo de la población local y estatal. Este ESCAPARATE informa sobre el periplo de esta obra, de interesantes tonalidades legales, técnicas y sociales.

\section{Contextualización}

En virtud de la Ley Federal sobre Monumentos y Zonas Arqueológicos, Artísticos e Históricos (INAH 1972: artículos 36 y 52), el hurto de la obra en comento, considerada monumento histórico en un recinto religioso, constituyó un delito, aspecto legal que da la pauta para considerar algunas de las consecuencias de este tipo de infracciones en la fábrica histórica y social tanto a escala local como estatal.

La comunidad de Lomas de Bracho, nombrada así desde el siglo XVIII en honor de un notable minero, Domingo Tagle Bracho, ubicada al norte de la ciudad de Zacatecas, posee una interesante historia, cuyos restos configuran una herencia cultural patrimonial que, generación tras generación, se ha sumado a variadas tradiciones vivas que tienen su origen hace más de un siglo (Zaldívar Ortega 1998:83): algunos la identifican como el origen de la ciudad de Zacatecas (Zaldívar Ortega 1999:34). Ahí se edificó la que sería la primera iglesia del estado, cuyas ruinas (Figura 2) aún se observan en la vecindad de la actual capilla de San Juan Bautista, erigida a finales del siglo XIX (Figuras 3 y 4). 


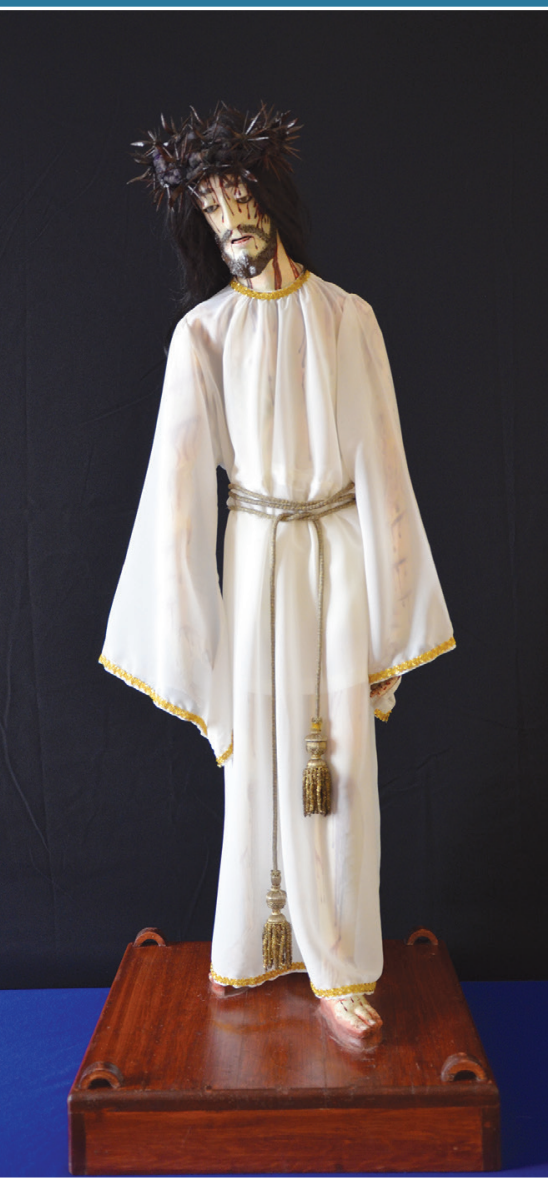

Figura 1. Vista frontal de la escultura Cristo divino preso (Fotografía: Diana Ugalde Romo 2012; cortesía: Centro INAH Zacatecas).

Figura 2. Ruinas de la primera capiIla de Zacatecas, edificada en Lomas de Bracho (Fotografía: Diana Ugalde Romo 2012; cortesía: Centro INAH Zacatecas).

Figura 3. Vista de la capilla de San Juan Bautista, Lomas de Bracho, Zacatecas, en 1890 (Fuente: Diana Ugalde Romo 2012).

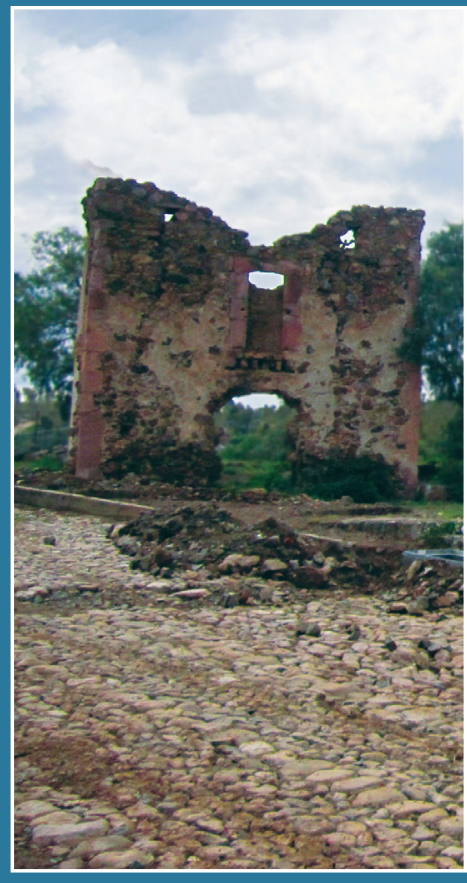

Tanto el recinto religioso, de gran relevancia histórica, como su beIlo emplazamiento paisajístico —un contorno formado por un suave lomerío-, constituyen el escenario de una de las fiesta de moros y cristianos más interesante, original, pintoresca y abigarrada de que se tiene noticia en nuestro país: la morisma de Bracho (Del Hoyo 1996:79). Ésta (Figura 5) se celebra anualmente en los últimos viernes, sábado y domingo de agosto. Incluye tres días y tres noches de festividades públicas que tienen lugar no sólo en la capiIla de San Juan Bautista y la pequeña plazoleta aledaña sino también en algunos edificios y calles de la población y, fiel a su marco natural, en el inmenso escenario de las lomas y montañas que se extienden hacia el norte (Del Hoyo 1996:80); de hecho, es principalmente en estos últimos espacios donde se realizan las morismas, entendiendo el término como una multitud de moros:
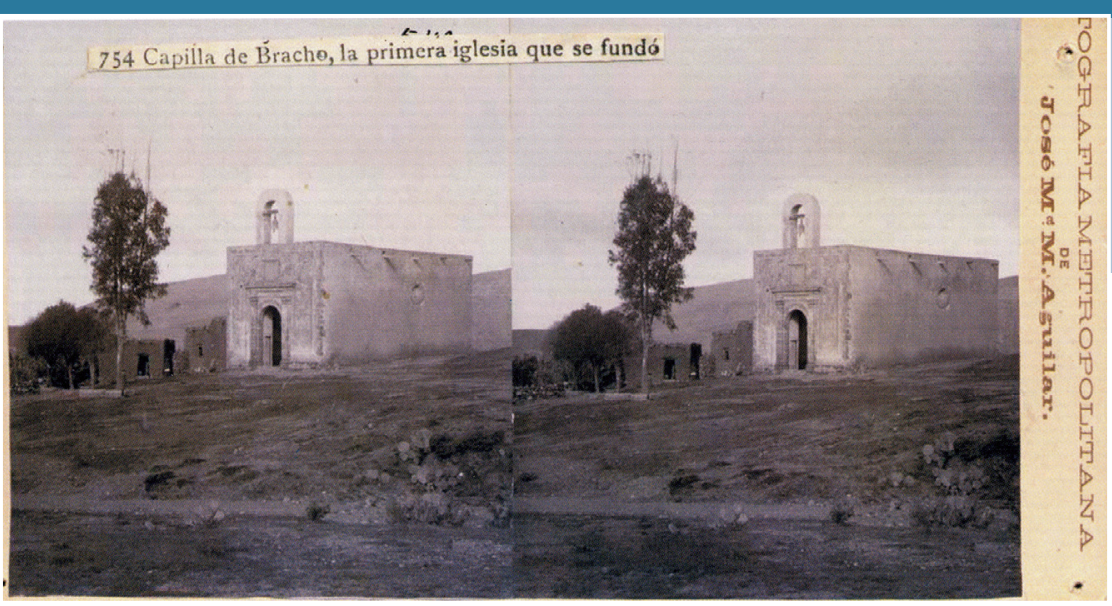

Las personas que ejecutan el ritual no son figurantes de una obra teatral, sino miembros de la Cofradía de San Juan Bautista. Los hay vestidos de romanos, de moros, de turcos, de decimonónicos soldados mexicanos o franceses del Segundo Imperio. Muchos llevan gafas de sol, como en las fiestas de moros y cristianos del Levante español, porque el astro rey aprieta. Y unos empuñan espadas, otros alfanjes, algunos fusiles con o sin bayonetas... (Díaz Viana 2001:1074)

Durante estos festejos se desarroIlan, adicionalmente, diversas misas tanto en la capilla de San Juan Bau- tista como en la cofradía del mismo nombre, ésta, sede de la instancia que se encarga de toda la organización de las conmemoraciones, en las que la pieza que me ocupa tiene una importante participación en la Procesión del Silencio, el acto religioso de mayor importancia en el estado de Zacatecas (Figura 6).

La Procesión de Silencio, cuyo origen se remonta al siglo XIX, tiene lugar cada Viernes Santo en las calles del Centro Histórico de Zacatecas, la ciudad capital. En ella cientos de feligreses católicos recrean escenas y representan personajes religiosos tales como el calvario de la soledad, la oración del huerto, el divino preso, 


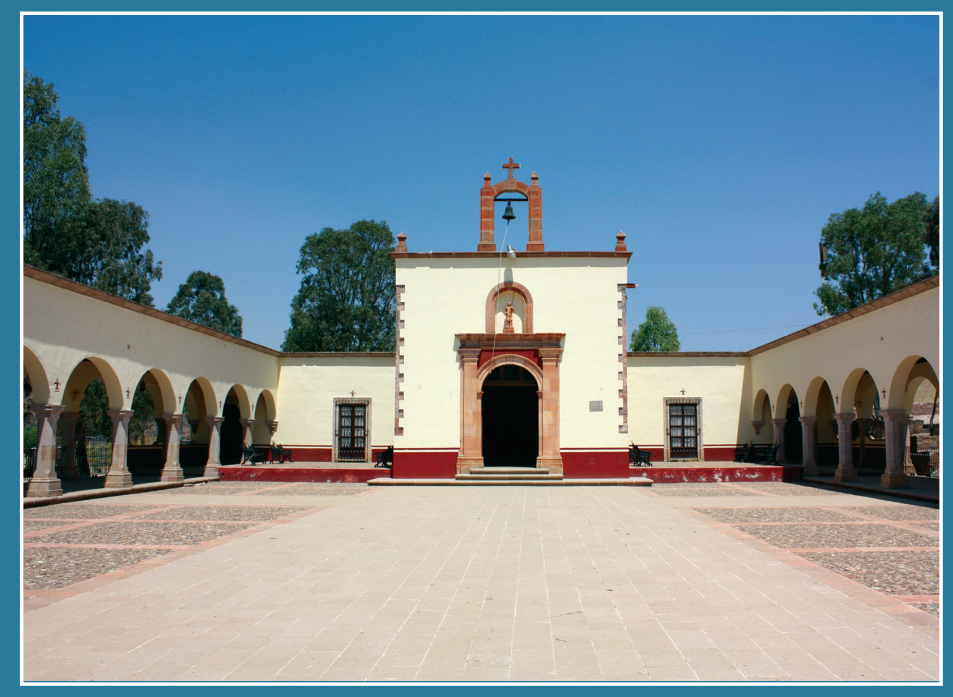

Figura 4. Construcción actual de la capilla de San Juan Bautista, Lomas de Bracho, Zacatecas (Fotografía: Diana Ugalde Romo 2012).

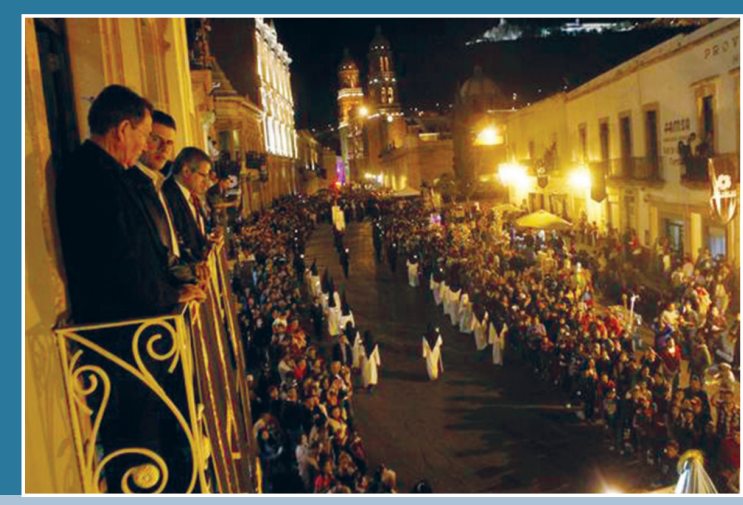

$\Delta$

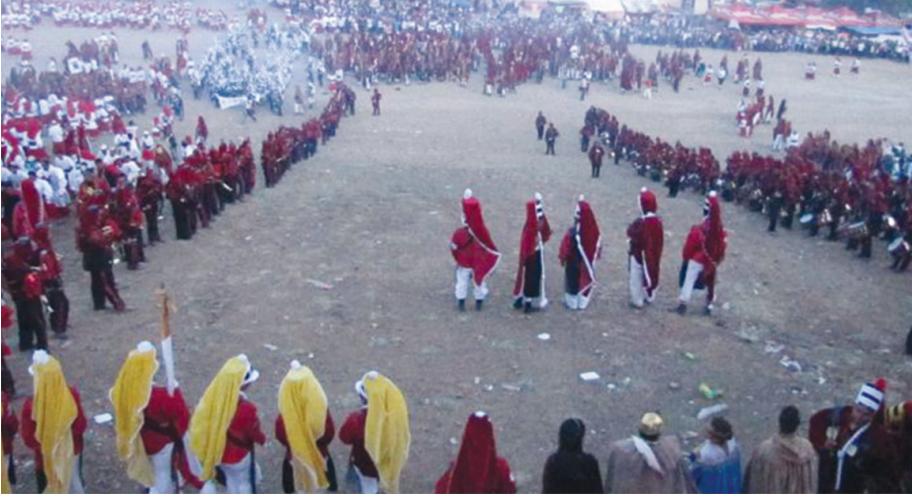

A Figura 5. Las morismas de Bracho (Fuente: Z@L 2013).

la flagelación, la Verónica, el Santo Encuentro, la piedad, la Virgen de los Dolores, el Santo Entierro y otros relacionados con la Semana Mayor de la Iglesia Apostólica Romana. Si bien la procesión se realiza en otras partes del país, como Querétaro y San Luis Potosí, la zacatecana destaca por su tradición y su alcance, con millares de asistentes en fechas recientes, según estimaciones de la prensa local (Z@L 2014).

\section{Valoración}

Con base en la anterior contextualización, es posible afirmar que el Cristo divino preso es una pieza úni- ca y de relevante importancia, reflejada en múltiples valores que son significativos tanto para la comunidad estatal como para la local: por un lado, al ser integrante - junto con otras imágenes de características y procedencias diversas - de la Procesión del Silencio, constituye un elemento patrimonial protagónico del marco de sacralidad de mayor trascendencia en el estado; por el otro, al tratarse una pieza central del patrimonio sacro de Lomas de Bracho y de su más importante tradición, las morismas de Bracho, es considerada como un elemento de devoción y cohesión comunitarias en la escala local.
En este sentido, la acción de sustraer ilícitamente la escultura Cristo divino preso de la capilla de San Juan Bautista en Bracho significó para los feligreses católicos del estado de Zacatecas un despojo, para la historia y tradiciones de los zacatecanos, una mutilación y, en particular, para los habitantes de Lomas de Bracho, un ataque a su identidad.

\section{El rescate}

Si bien la preservación de los bienes que forman parte del legado cultural de Zacatecas ha sido un tema que ha estado presente en la sociedad de esa entidad, como lo muestran las tareas de investigación, conservación y difusión del patrimonio cultural ahí realizadas y la suntuosidad de sus edificios históricos, museos, zonas arqueológicas y otros espacios existentes, han prevalecido ciertas deficiencias de atención profesional en cuanto a la catalogación, seguridad, 

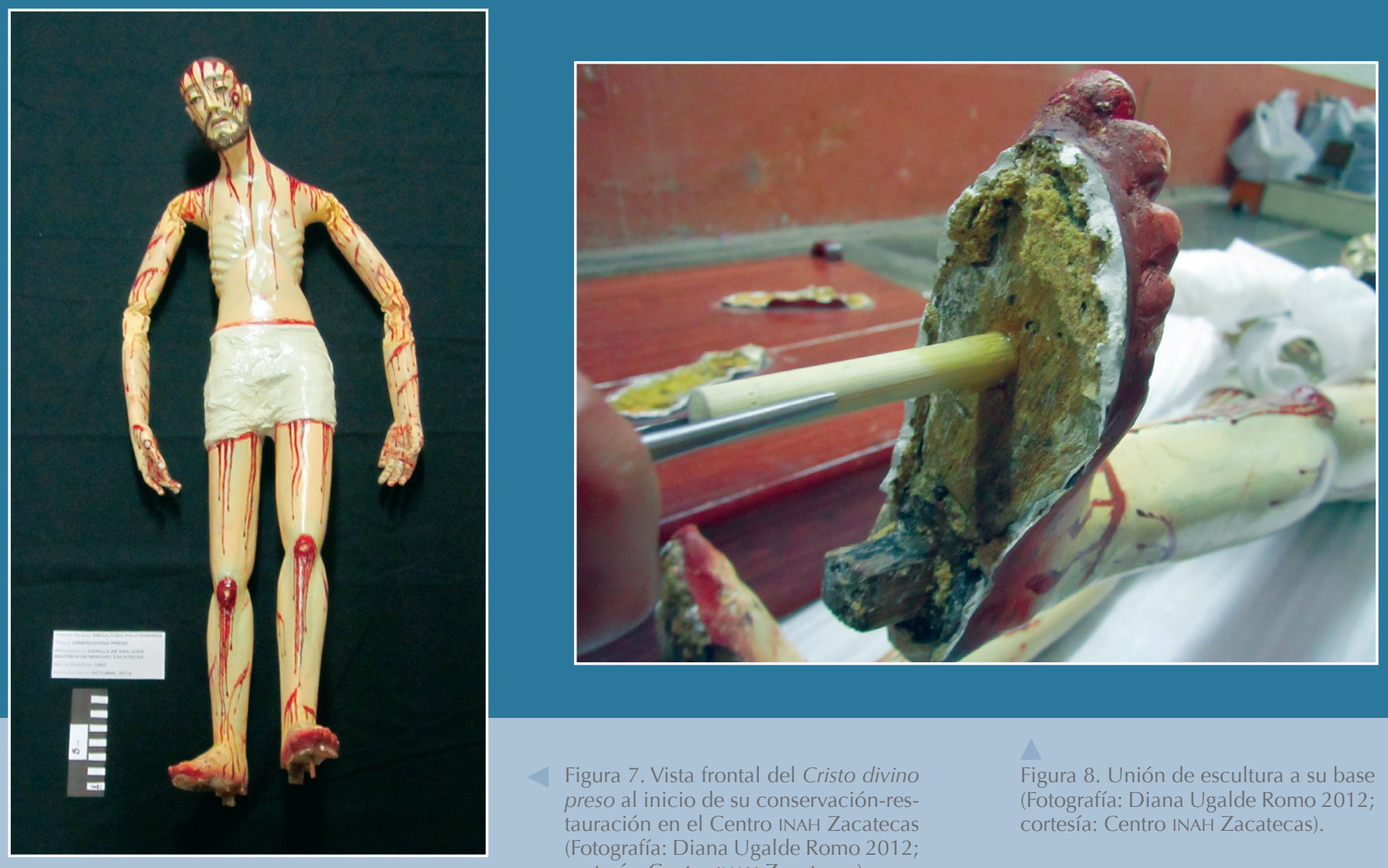

Figura 7. Vista frontal del Cristo divino preso al inicio de su conservación-restauración en el Centro INAH Zacatecas (Fotografía: Diana Ugalde Romo 2012; cortesía: Centro INAH Zacatecas).
Figura 8. Unión de escultura a su base (Fotografía: Diana Ugalde Romo 2012; cortesía: Centro INAH Zacatecas). prevención de riesgos y conservación-restauración del contenido de bienes muebles, particularmente en recintos religiosos, ilustradas por el robo del Cristo divino preso. No obstante, es necesario subrayar los aspectos positivos: gracias al trabajo previo de registro por parte de especialistas del área de conservación y restauración del Centro INAH Zacatecas, esta escultura contaba, antes de su hurto, con un número de inventario y una ficha de registro dentro del Catálogo de bienes muebles del estado de Zacatecas (Berthier 2003:121), lo cual permitió disponer de información esencial lo mismo para conducir las acciones de búsqueda que para proceder a la identificación de la obra y realizar un cabal seguimiento del proceso legal rumbo a su recuperación.

Cabe señalar que, dado que la obra presentaba daños derivados de una manipulación poco cuidadosa durante el ilícito, el Centro INAH
Zacatecas decidió llevar a cabo su conservación-restauración antes de devolverla a la comunidad de Lomas de Bracho.

\section{La intervención}

El proceso de conservación-restauración de esta escultura, cuyo principal objetivo fue recuperar la estabilidad de la escultura en lo que corresponde tanto a su materia como a la imagen del Cristo, se basó en el "Proyecto de conservación y restauración de la escultura policromada denominada Cristo divino preso o Cristo atado a la columna, perteneciente al Templo de San Juan Bautista en Bracho, Zacatecas" (Ugalde Romo 2012). Este documento plasmó la metodología del trabajo que había de realizarse, consistente en las siguientes fases: estudio de antecedentes históricosculturales del contexto y de la obra en sí; descripción del bien cultural; análisis de materiales constitutivos y técnica de manufactura; detección de intervenciones anteriores; diagnóstico de estado físico; propuesta de intervención y recomendaciones. En seguimiento de los trámites legales pertinentes, las acciones del área de conservación-restauración se ejecutaron durante los meses de octubre y noviembre del 2012.

De manera general, se identificó que las alteraciones más graves ocurridas en la obra durante el robo fueron: el desprendimiento de la escultura de su base; la pérdida del dedo meñique de la mano derecha; diversas grietas y fisuras en diferentes zonas, así como pérdidas puntuales en la policromía (Figura 7).

Consecuentemente, los tratamientos de conservación-restauración se enfocaron en (Ugalde Romo 2013):

- Restablecer la unión de la escultura a su base y volverla a poner en pie, asegurando su estabilidad, 

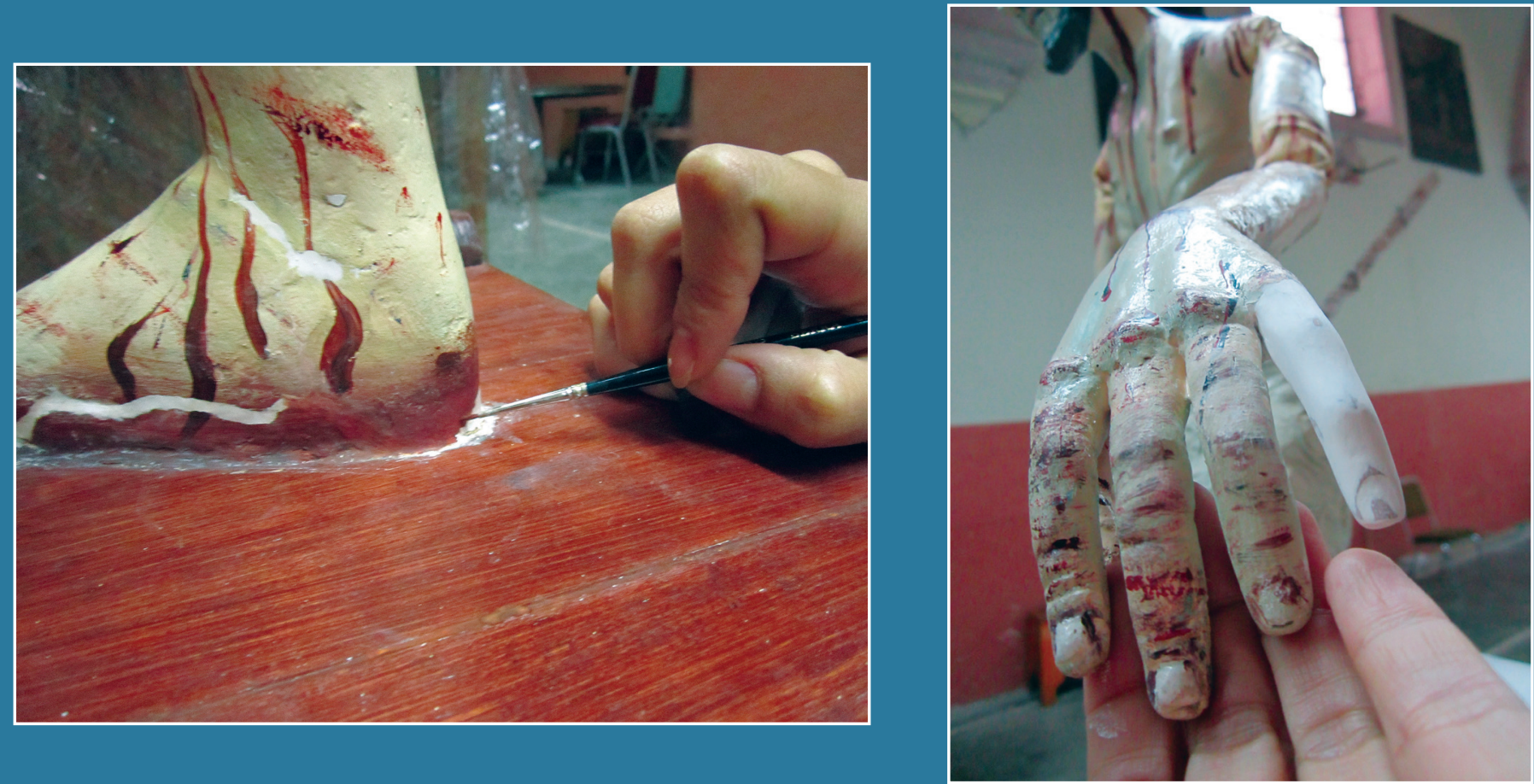

Figura 9. Resanes y reintegración cromática (Fotografía: Diana Ugalde Romo 2012; corteFigura 10. Reposición del dedo meñique (Fotografía: Diana Ugalde Romo 2012; cortesía: sía: Centro INAH Zacatecas).

para lo cual, mediante la utilización de cola animal como adhesivo y pasta de carbonato de calcio mezclado con cola animal como material para resanes, se colocaron pernos de bambú (Figura 8).

- Estabilizar materialmente la escultura, por lo que se realizaron: inyección en grietas y fisuras de adhesivo, resanes de pasta y reintegración cromática (Figura 9).

- Estabilizar la imagen de la obra, lo que llevó a la reposición, con madera de cedro rojo, del dedo meñique ${ }^{1}$ (Figura 10).

Cabe señalar que también los accesorios de la escultura, tales como

1 Es importante mencionar que la escultura cuenta, como parte de una intervención anterior, con un repinte total, sin registro, sobre la probable capa pictórica original, de la que se tiene poca evidencia. la peluca y la vestimenta, se sometieron a procesos de intervención que consistieron en limpieza superficial, lavado acuoso y, en el caso de la corona de espinas, unión de fragmentos (Ugalde Romo 2013).

Además, vale la pena subrayar que en el proceso prevaleció una perspectiva integrada, ya que las acciones de conservación-restauración no se limitaron al tratamiento directo de la obra, sino, adicionalmente, se buscó dotar a la comunidad de Lomas de Bracho del conocimiento necesario en cuanto a medidas de seguridad, conservación preventiva y manejo de riesgos para esculturas policromadas en recintos religiosos (Figura 11).

\section{Conclusiones}

La escultura del Cristo divino preso fue devuelta a la capilla de San Juan Bautista, Lomas de Bracho, Zacatecas, el 30 de enero de 2013, con la presencia de representantes de las diferentes instancias que participaron en su recuperación, tales como la policía estatal de Zacatecas, la Procuraduría General de la República (PGR), la Coordinación Nacional de Conservación del Patrimonio Cultural (CNCPC-INAH) y el Centro INAH Zacatecas, entre otros (El Sol de Zacatecas 2013). En esta fecha se convocó a la comunidad con el fin de informarla sobre los tratamientos Ilevados a cabo y sensibilizarla respecto de la importancia de la conservación de bienes culturales en recintos sacros. Ahí se apuntaron, entre otros aspectos, puntos esenciales de conservación preventiva derivados del análisis del caso aquí descrito: la relevancia del registro y catalogación de bienes culturales, la necesidad de establecer medidas de seguridad en los recintos religiosos, las ventajas del trabajo entre instancias gubernamentales y los beneficios de las alianzas con la sociedad. 
Figura 11. Entrega de obra al lugar de $>$ procedencia (Fotografía: Jorge Luis Pereira 2013; cortesía del autor).
En la actualidad, la capilla de San Juan Bautista de Lomas de Bracho cuenta con cámaras de videograbación y medidas de protección en sus accesos para optimizar la seguridad del templo y, en particular, de su valioso contenido. Paradójicamente, la enojosa experiencia del robo de la escultura ha concienciado a la comunidad sobre el significado e importancia de su legado cultural, lo que refrenda que una de las tareas fundamentales de nuestra labor profesional como restauradores consiste en coadyuvar a informar a la sociedad acerca de la importancia, el valor y el significado de las obras que forman parte de su patrimonio. La conservación, ciertamente, es tarea de todos.

\section{Agradecimientos}

Se agradece la participación en la elaboración de este proyecto a la Procuraduría General de la República (PGR), la policía estatal y municipal de Zacatecas, la Coordinación Nacional de Conservación del Patrimonio Cultural (CNCPC-INAH) y el Centro INAH Zacatecas, así como, por su apoyo, al consejo editorial de la revista Intervención.

\section{Referencias}

\section{Berthier, Eugenia}

2003 Catálogo del patrimonio cultural mueble en los recintos religiosos del estado de Zacatecas, Zacatecas, Centro INAH Zacatecas/INAH. $\mathrm{CO}$

2013 "Contraluz online", documento electrónico [página web] disponible en [www.contraluzonline.com], consultado en abril del 2013.

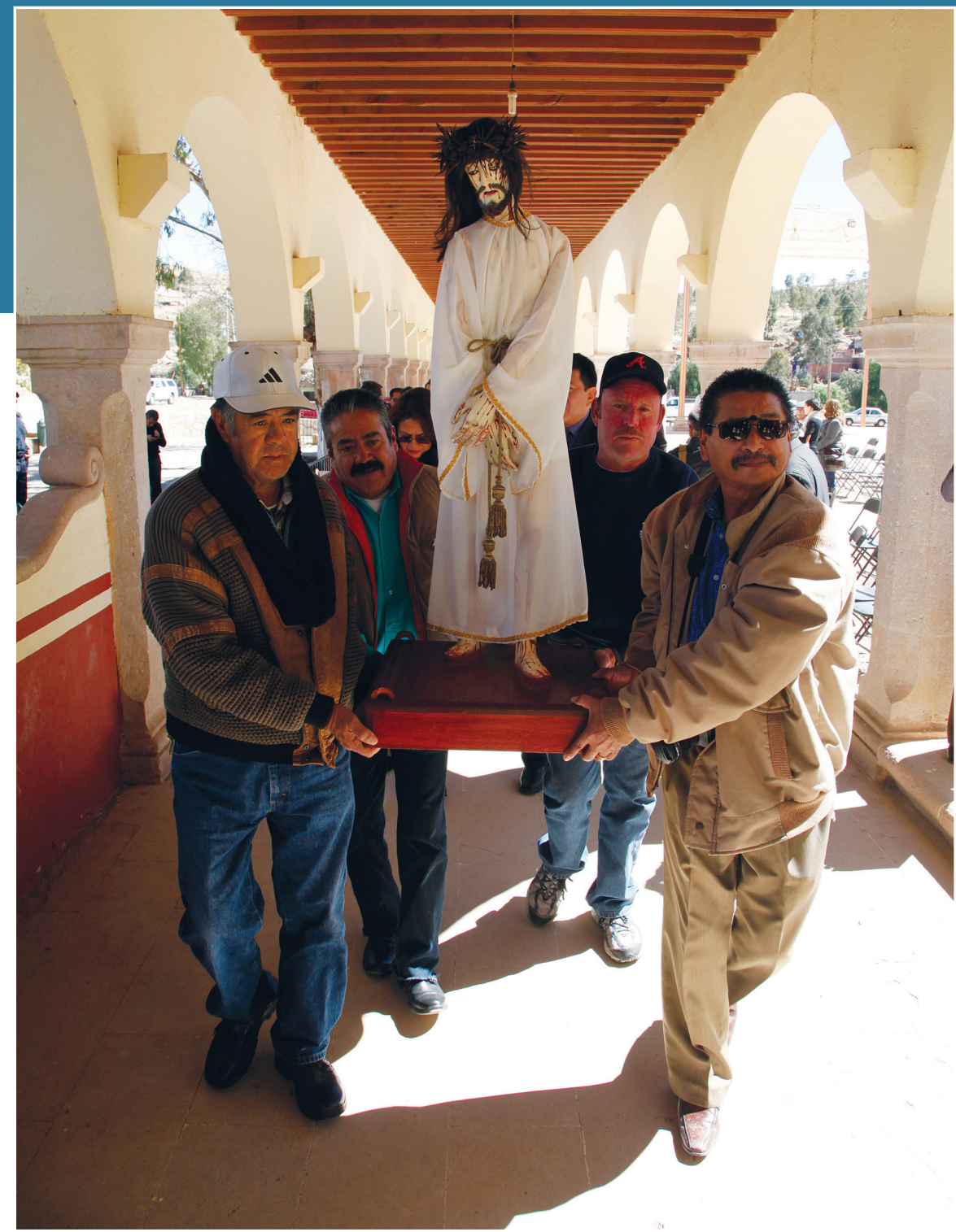

Díaz Viana, Luis

2001 "Juego de espejos entre identidades: las representaciones rituales de asunto carolingio en España y América", en Joaquín Álvarez Barrientos, Óscar Cornago Bernal, Abraham Madroñal Durán, Carmen MenéndezOnrubia (coords.), En buena compañía: estudios en honor de Luciano García Lorenzo, Madrid, Consejo Superior de Investigaciones Científicas (CSIC).

El Sol de Zacatecas

2013 "Retorna el divino preso a la capilla de Bracho", El Sol de Zacatecas, 30 de enero, documento electrónico disponible en [www.oem.com.mx/elsoldezacatecas/notas/n2862922.htm], consultado en mayo del 2014.
Hoyo, Eugenio del

1996 La ciudad en estampas. Zacatecas 1920-1940, México, Artes de México (Libros de la Espiral).

$\mathrm{INAH}$

1972 Ley Federal sobre Monumentos y Zonas Arqueológicos, Artísticos e Históricos, México, INAH.

Ugalde Romo, Diana

2012 "Proyecto de conservación y restauración de la escultura policromada denominada 'Cristo divino preso' o 'Cristo atado a la columna', perteneciente al Templo de San Juan Bautista en Bracho, Zacatecas", mecanoescrito, Zacatecas, Centro INAH Zacatecas. 2013 "Informe de los procesos realizados durante la intervención de conser- 


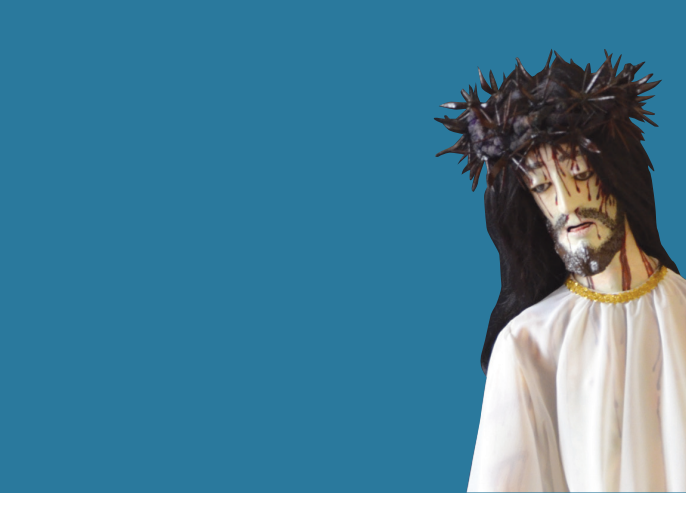

vación y restauración de la escultura policromada denominada 'Cristo divino preso' o 'Cristo atado a la columna', perteneciente al templo de San Juan Bautista en Bracho, Zacatecas", mecanoescrito, Zacatecas, Centro INAH Zacatecas.

Zaldívar Ortega, Juan J.

1998 Las morismas de Bracho: investigación histórica de la fiesta de moros y cristianos, vol. 1, Zacatecas, Fondo de Cultura Zacatecana (Antropología, 5).

\section{Resumen}

A casi un año de que fue robada, la escultura policromada del Cristo divino preso regresó a su lugar de procedencia: la capilla de San Juan Bautista en Bracho, Zacatecas, México, mediante una operación cuyo éxito se alcanzó en buena medida gracias a que se contaba con una ficha de registro de la pieza como parte del catálogo del patrimonio cultural mueble en los recintos religiosos del estado. Después de dar seguimiento a los trámites legales correspondientes, se elaboró y ejecutó el proyecto de conservación-restauración de la escultura, el cual culminó con acciones de conservación preventiva y sensibilización dirigidas a miembros de la comunidad de Bracho. Este ESCAPARATE reporta los incidentes del caso, el cual reitera la importancia del registro y la catalogación de bienes culturales como requisito indispensable para su conservación.

\section{Palabras clave}

robo; escultura; danza de la morisma; Bracho; Zacatecas; tráfico ilícito
1999 Los fundadores de Zacatecas, Zacatecas, Fondo de Cultura Zacatecana.

Z@L

2014 "Procesión del Silencio 2014 en Zacatecas reúne a miles de fieles", Zacatecas@ @ínea (Z@L), documento electrónico disponible en [http://zacatecasonline.com.mx/cultura/ cultura/38188-prosecion-silencio-2014.html], consultado en junio del 2014.

\section{Abstract}

Almost one year after the polychrome sculpture of Cristo divino preso (Christ, Divine Prisoner) got stolen, it was returned to its place of origin, La Capilla de San Juan Bautista (Saint John the Baptist Chapel), in Bracho, Zacatecas, Mexico. Its return operation was successful mainly because of the existence of a registration form as part of the catalogue of movable cultural heritage of religious buildings of the state.

After a follow-up on the legal formalities, a conservation-restoration project was set up and carried out for the sculpture. This concluded with actions of preventive conservation and awareness-raising directed towards the members of the Bracho community. This GALLERY reports the incidents of the case, reaffirming the importance of registration and cataloguing of cultural property as key requirements for its preservation.

Key works

theft; sculpture; Christian and Moors dance; Bracho; Zacatecas; illicit traffic

Título en inglés. The Recovery of the Cristo divino preso (Christ, Divine

Prisoner) from Bracho in Zacatecas (Mexico) 